\title{
Work experiences of qualified immigrants: a review of theoretical progress
}

\author{
Ali Dehghanpour Farashah \\ School of Business, Society and Engineering, Mälardalen University, \\ Västerås, Sweden, and \\ Tomas Blomquist \\ Umeå School of Business, Economics and Statistics, Umeå University, Umeå, Sweden
}

Theories for studying qualified immigrants

1063

Received 31 January 2019 Revised 13 November 2019 29 June 2020

Accepted 6 November 2020

\begin{abstract}
Purpose - Qualified immigrants (QIs) and their work experiences have been studied using a wide variety of theoretical approaches with divergent characteristics. This paper reviews theoretical progress and proposes directions for future research and practice.

Design/methodology/approach - Using relevant keywords, articles indexed by Web of Science in management, business, industrial relations and applied psychology were systematically searched for and analysed. In total, 60 theoretical articles published during 2008-2018 were included. The theoretical progress and future theoretical and practical challenges were organised based on the notions of equality, diversity and inclusion. Findings - Eight theoretical approaches utilised to study QIs' work experiences were recognised: (1) human capital theory, (2) career capital theory, (3) theory of practice, (4) intersectionality, (5) social identity theory, (6) sensemaking, (7) cultural identity transition and (8) the career-centred approach. The contributions and limitations of each theoretical lens were then scrutinised. Overall, research on QIs still lacks a comprehensive theoretical framework. As a step towards that, the paper proposes considering the role of organisations and labour market intermediaries, strategic view over the immigrant workforce, agency-institution play, identitycapital play and host-immigrant play.

Research limitations/implications - The focus is on theory development and empirical papers with no clear theoretical foundation are excluded.

Originality/value - This review is the first attempt to summarise and direct the divergent research on the topic. The main contribution is setting an agenda for future research, particularly by proposing the elements of a comprehensive theoretical framework for studying QIs in the workplace.
\end{abstract}

Keywords Immigration, Qualified immigrant, Employment, Equality, Diversity, Theoretical review Paper type Literature review

\section{Introduction}

Immigrant workers contribute significantly to global social and economic development. However, migration is a complex issue that presents challenges for immigrants, in terms of access to the labour market and career development, and for organisations and host societies, in terms of increased diversity (Burke and $\mathrm{Ng}$, 2006). With a recent rise in research on immigrant workers, academics and practitioners have documented several key, permeating issues regarding migration and global careers (Cohen et al., 2011). However, there has been no systematic review devoted solely to immigrant workers, similar to reviews regarding expatriate workers (e.g. Baruch et al., 2016; Shaffer et al., 2012).

(C) Ali Dehghanpour Farashah and Tomas Blomquist. Published by Emerald Publishing Limited. This article is published under the Creative Commons Attribution (CC BY 4.0) licence. Anyone may reproduce, distribute, translate and create derivative works of this article (for both commercial and noncommercial purposes), subject to full attribution to the original publication and authors. The full terms of this licence may be seen at http://creativecommons.org/licences/by/4.0/legalcode

This research was supported by Swedish Research Council for Health, Working life and Welfare (FORTE) under grant Dnr: 2017-00285.

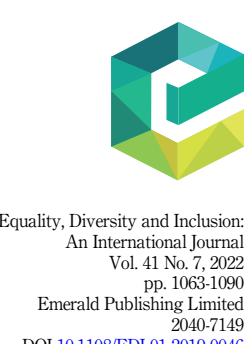

DOI 10.1108/EDI-01-2019-0046 
EDI

41,7

1064

International migrant workers are a diverse group. The literature mainly identifies three types of immigrant workers: assigned expatriates, self-initiated expatriates (SIEs) and immigrant workers (Farcas and Goncalves, 2017). An expatriate is a migrant worker relocated by a corporate to a foreign subsidiary for a specific mission; they receive full support from the corporate during their temporary stay abroad (McNulty and Brewster, 2017). By contrast, SIEs decide to move and work abroad of their own volition but, like expatriates, their stay is temporary (Farcas and Goncalves, 2017). Like SIEs, immigrant workers are not supported by a corporation at the time of arrival; unlike SIEs, however, they intend to permanently reside in the host country and eventually acquire citizenship (Przytuła, 2015). These groups of immigrants differ significantly in their motives, needs and attitudes regarding the work and integration context (Baruch et al., 2013; Haines et al., 2008).

This paper focusses primarily on qualified immigrants (QIs). Among developed countries, there is a trend towards policies that aim to control migration flows by selectively attracting highly QIs (Emilsson, 2015). However, QIs mostly remain a “forgotten minority”, especially in management and organisation research (Binggeli et al., 2013). Focussing on QIs is vital from the perspectives of equality, diversity and inclusion (EDI): despite the efforts of QIs and host societies, matching their employment to their skill level remains challenging (Elrick, 2016; Ette et al., 2016). Researchers and policymakers have recently recognised that QIs as a group require independent labour markets initiatives and treatment, and the number of studies on this group has increased sharply in recent years (Hajro et al., 2019). This review attempts to demonstrate the breadth of research on QIs' work experiences and understand the theoretical insights of existing literature. This review tackles two research questions:

$R Q 1$. Theoretical progress: Which theories have been used to study qualified immigrants' work experiences? What is our state-of-the-art understanding of qualified immigrants' EDI experiences in the workplace, as illuminated by theories?

RQ2. Challenges ahead: From a theoretical perspective, what relevant constructs and areas of research are lacking and what are the main theoretical gaps? Subsequently, which directions should future research take to offer new insights on qualified immigrants' EDI experiences in the workplace? From a practical perspective, what should immigrants, employers and other social actors do to enhance EDI in the workplace for qualified immigrants?

By addressing these research questions, we contribute to QI research by organising the fragmented and rapidly growing literature, providing an in-depth picture of recent progress. We also expand on prior enquiries by proposing new directions for both research and practice regarding EDI in the workplace for QIs.

The remainder of this paper is organised as follows. We first define the concept of QI and clarify the process of identifying relevant research. Then, we detail the eight identified theoretical approaches, discussing the contributions and limitations of each approach, as well as their main empirical findings. To show the commitment of the research to creating positive change, we also discuss practical initiatives and mechanisms to enhance EDI in the workplace. We also propose a future research agenda.

\section{Defining QIs and work experiences}

QIs have diverse attributes in terms of reasons for migrating, level of human capital or social connections, degree of cultural closeness to the host culture and level of motivation to integrate. They are also diverse with respect to the traditional diversity dimensions of race, age, ethnic and national origin, gender and disability (Binggeli et al., 2013). However, QIs are 
considered to have some common attributes, such as agency in their international relocation with the intention to enhance their career (Cerdin and Selmer, 2013; Doherty et al., 2013). Following Cerdin et al. (2014), we define QIs as immigrants with a foreign university education who have moved on a permanent basis to reside and work in countries other than their own. Specifically, they have been educated in a country other than the host country (mainly the "Global South"), as QIs' foreign education is found to be associated with higher unemployment and a larger earnings gap between recent immigrants and native-born citizens, whereas local education decreases this gap (Banerjee and Lee, 2015; Mahmud et al., 2014).

Work experiences are events or activities that occur as part of QIs' international mobility and influence their motivation and performance, with potential subsequent effects on their career trajectory (Tesluk and Jacobs, 1998). Work experiences include periods of job-seeking and employment. They might also include experiences beyond the workplace, such as the effects of migration on well-being, happiness or family conflicts.

\section{Method}

\section{Data collection}

The first step of a literature review is to develop a database of relevant research. Using the Web of Science database, potentially relevant research was identified by conducting structured keyword searches in the abstract, title and keywords of indexed papers. The search comprised strings of all possible combinations of ("skilled [im]migrant" OR "professional [im]migrant” OR "qualified [im]migrant") AND ("work” OR “employment" OR “career" OR "labo[u]r market integration"). The search returned 1,196 articles. Therefore, the search scope was limited to studies indexed by Web of Science in management and organisation, which are considered the most relevant fields to work experience. The initial search returned $n_{1}=180$ articles. Identified articles were then exported to EndNote citation manager software for further analyses. Initial reading of the title and abstract of all identified works led to the exclusion of $n_{2}=36$ articles: most focussed on low-skilled immigrant workers (e.g. Busch et al., 2017; Hopkins et al., 2016; Srour et al., 2017) or issues unrelated to work, such as health (e.g. Bernal et al., 2017; Yakushko, 2010) or remittance (e.g. McDonald and Valenzuela, 2017); the others focussed on second-generation immigrants (e.g. Baycan et al., 2012; Busch et al., 2017), minority native-born citizens (e.g. Alvarado and Ricard, 2013; Behrenz et al., 2016) or illegal foreign workers (e.g. Kao, 2017).

For articles whose title and abstract suggested potential relevance to QIs' experiences $\left(n_{3}=144\right)$, the full-text version was obtained and examined to determine eligibility for inclusion. In the full-text analysis phase, another $n_{4}=36$ articles were excluded. These focussed on: short-term temporary migration for work, study or an internship (e.g. Bahn, 2015; Hirt et al., 2017; Li et al., 2016; McKenna and Richardson, 2016; Toh et al., 2009; Zimmermann and Ravishankar, 2011); non-documented and unauthorised employment (e.g. Amuedo-Dorantes and Sevilla, 2014; Bohn and Owens, 2012; Marfleet and Blustein, 2011); non-skilled immigrants (e.g. Baxter-Reid, 2016; Bell et al., 2010; Friberg et al., 2014; Hagan et al., 2011; Lima and Martins, 2012); professional athletes with a short-lived career (Allmen et al., 2015; Ryba et al., 2016) or skilled SIEs (Ford and Kawashima, 2016; te Nijenhuis et al., 2014). We also excluded $n_{5}=60$ exploratory articles with no theoretical foundation (e.g. Asali, 2017; Bimrose and McNair, 2011; Flynn et al., 2011; Gericke et al., 2018; Harvey, 2012; Horverak et al., 2013; Liu et al., 2015; Manroop et al., 2013; Neville et al., 2014; Rissing and Castilla, 2016; van den Broek and Groutsis, 2016). By investigating the reference list of the articles, editorials and literature reviews, and based on suggestions from this paper's reviewers, $n_{6}=12$ additional theoretical articles were identified and included. Figure 1 presents an overview of the process of developing the database of relevant studies. A total of
Theories for studying qualified immigrants

1065 


\section{EDI 41,7}

Figure 1.

The process of developing the literature database

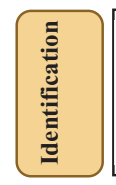

Search of the Web of Science database for works published on qualified immigrants from 2008 to May 2018 in management or organisation research fields (i.e. management, business, industrial relations, or applied psychology)
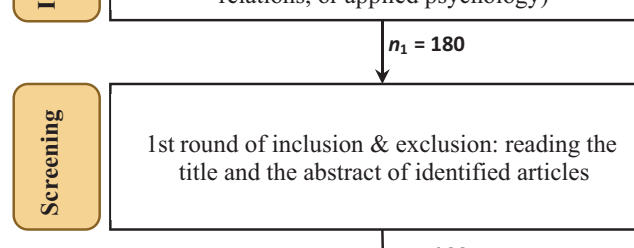

1st round of inclusion \& exclusion: reading the title and the abstract of identified articles

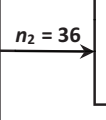

Articles that did not focus on qualified immigrants were excluded

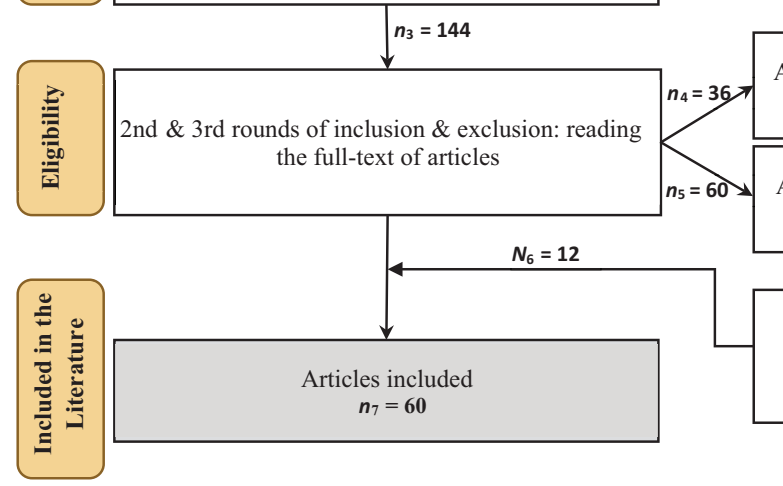

Articles that did not focus on qualified immigrants were excluded

Articles that did not have a theoretical foundation were excluded

Related articles cited in the articles, literature reviews, and editorials or suggested by the reviewers were included

$n_{7}=60$ articles which theoretically investigated QIs' work experiences were included in this literature review. These articles are listed in Appendix.

\section{Data analysis}

Each article was first subject to coding regarding the scope. A summary of the results is presented in Table 1. Most of the extant literature investigates migration to the "Global North". Regarding the destination country, existing studies mainly cover two geographical spans: countries with a points-based system for attracting (skilled) immigrants, such Canada and Australia, and European countries whose immigration system is mainly characterised by humanitarian aspects, such as easier family reunifications and asylum-seeking and a relatively generous welfare system. As shown in Table 1, most of the studied immigrants originated in the Middle East, China or South Asia. Table 2 overviews the management and organisation journals demonstrating interest in the work experiences of QIs. International Journal of Human Resource Management and Equality, Diversity and Inclusion: An International Journal are the two main outlets for relevant publications.

\section{Theoretical approaches to studying QIs' work experiences}

Researchers have adopted different theoretical approaches to analyse QIs and their experiences. Having an overview of the theoretical approaches used can inform a more nuanced understanding of current progress. The literature review reveals that QIs' work experiences have been studied from eight theoretical perspectives, which Table 3 outlines. The approaches can be roughly categorised into two groups. One group of theories concentrates on the type of variables explaining antecedents of the migration decision and particularly on the consequences of immigration in terms of employment and career 


\begin{tabular}{|c|c|c|}
\hline Scope & & \# Studies \\
\hline \multirow[t]{7}{*}{ Profession } & Medical profession & 4 \\
\hline & Accountants & 3 \\
\hline & Academics & 2 \\
\hline & IT professionals & 2 \\
\hline & Other professions & $3^{\mathrm{a}}$ \\
\hline & Mixed professions & $6^{\mathrm{b}}$ \\
\hline & No specific profession & 40 \\
\hline \multirow[t]{8}{*}{ Host country/region } & Canada & 16 \\
\hline & Australia & 12 \\
\hline & Western/Southern Europe & 10 \\
\hline & UK & 6 \\
\hline & Scandinavia & 4 \\
\hline & USA & 3 \\
\hline & Japan & 1 \\
\hline & Mixed sample or not specified & $8^{c}$ \\
\hline \multirow[t]{8}{*}{ Country/region of origin } & Middle East and North Africa & 8 \\
\hline & China & 5 \\
\hline & South Asia (India, Nepal, Pakistan) & 5 \\
\hline & Europe & 3 \\
\hline & Central/Latin America & 3 \\
\hline & Philippines & 1 \\
\hline & Norway & 1 \\
\hline & Mixed sample or not specified & 34 \\
\hline
\end{tabular}

Note(s): ${ }^{2}$ Scientists (biotechnology), Engineers and Managers, ${ }^{\mathrm{b}} \mathrm{IT}$ and Accounting (2), IT and Engineering, IT and Medical, Nursing and Engineering, and Regulated professions, ' Including France and Germany, Western Christian countries, the UK and US, countries in the United Nations Development Programme, the US and Canada, Canada and Spain and France
Theories for studying qualified immigrants

1067

\begin{tabular}{lc} 
Journal title & No. of articles \\
\hline International Journal of Human Resource Management & 12 \\
Equality, Diversity and Inclusion: An International Journal & 5 \\
Career Development International & 3 \\
International Journal of Manpower & \\
Journal of Vocational Behavior & 2 \\
Work, Employment and Society & \\
Asia Pacific Journal of Human Resources Management & Table 2. \\
Gender, Work and Organization & Distribution of articles \\
Human Resources for Health & by journal \\
Journal of International Migration and Integration & 1
\end{tabular}

outcomes. The second group is characterised by focus on the acculturation process, the challenges for immigrants and their host society, and the coping strategies. Following Lohaus and Habermann (2019), the former are labelled content theories and the latter are labelled process theories.

The content theories include human capital theory, career capital theory, intersectionality and cultural identity transition. The process theories include theory of practice, sensemaking and social identity theory. The articles and associated theories are presented in Appendix. In the following sections, we analyse the contribution of each theoretical approach to the 
EDI
41,7

\begin{tabular}{lllcll}
\hline $\begin{array}{l}\text { Theoretical } \\
\text { approach }\end{array}$ & Origin & $\begin{array}{l}\text { Leading } \\
\text { author(s) in the } \\
\text { field of origin }\end{array}$ & $\begin{array}{c}\text { No. of } \\
\text { articles }\end{array}$ & Category & Main focus \\
\hline $\begin{array}{l}\text { Human capital } \\
\text { theory }\end{array}$ & Economics & $\begin{array}{l}\text { Shultz (1961), } \\
\text { Becker (1962) }\end{array}$ & 13 & Content theory & $\begin{array}{l}\text { Individual-level knowledge, } \\
\text { skills, abilities, personality and } \\
\text { social attributes as determinant }\end{array}$
\end{tabular}
social attributes as determinants of migration and its

1068

Career capital theory

Theory of practice

Sensemaking

Cultural identity transition

Social identity theory

Intersectionality

Career-centred approaches

Table 3.

Theoretical approaches to studying qualified immigrants' work experiences
Feminist studies

Crenshaw

(1991)

Bourdieu

$(1977,1986)$

Management

and

Weick (1995),

Helms Mills

Organisation

et al. (2010)

Tajfel and

Turner (1986)

8

Content theory

Content theory

consequences (e.g. employment and wage)

Individual human, social and motivational capital, in interaction with organisational characteristics and strategies, determine migrants' career prospects

8 Process theory

A combination of multi-level, individual capital and agency (habitus) and the institutional framework (field) determine work experiences and career strategies

Explains the cognitive processes and strategies of QIs in managing barriers to their career transition and development Employers' behaviour is often associated with stereotypes, and subtle discrimination leads to adverse selection of QIs Intersection of individual gender, migration status, country of origin and religion with institutional and cultural pressures affects power relations in the host society

Psychology $\quad$ Berry (1997) 4 Content theory

Identifies different outcomes of acculturation (4 types of cultural transition in terms of attachment to the culture of country of origin and host country) and the associated antecedents and career outcomes

\begin{tabular}{|c|c|c|c|c|}
\hline $\begin{array}{l}\text { Management } \\
\text { and } \\
\text { Organisation }\end{array}$ & $\begin{array}{l}\text { Various } \\
\text { scholars }\end{array}$ & 9 & $\begin{array}{l}\text { Loosely } \\
\text { specified } \\
\text { theoretical } \\
\text { concept }\end{array}$ & $\begin{array}{l}\text { Personal choices, individual and } \\
\text { organisational career } \\
\text { management strategies, and } \\
\text { destination country institutions } \\
\text { affect QIs career outcomes }\end{array}$ \\
\hline
\end{tabular}

research area (i.e. QIs' work experiences), summarise the related empirical findings and consider each approach's limitations.

Human capital theory (HCT)

Contribution to the research area: Human capital theory (HCT) prevails in the study of migrants. Human capital refers to the knowledge, skills, abilities and other characteristics (KSAOs) that individuals learn and develop through education and training. Rooted in economics and the seminal works of Schultz (1961) and Becker (1962), HCT is based on the idea that migration is an investment and individuals may migrate and sacrifice short-term security for the sake of future pecuniary and non-pecuniary returns, such as higher salaries, better employment opportunities and better quality of life. For example, Harvey (2012) found 
that British scientists are motivated to move to the United States by professional opportunities, whereas Indian scientists are mainly driven by educational opportunities. In short, HCT explains why people migrate through a cost-benefit perspective.

The principal theoretical assumption of HCT in migration research is that the decision to migrate is logical and pertains to the rate of return from migration. According to HCT, a QI's human capital can explain their labour market outcome in the new country. As an early theory in migration study, HCT emphasises human capital as the key predictor of career success: the better a migrant's knowledge and skills, the better their career outcomes (Syed, 2008). Therefore, individuals might consider international mobility as moving towards a market where their human capital is valued more. Accordingly, in our research context, HCT mainly explains the choices (i.e. reasons to migrate) and consequences (i.e. labour market outcomes) associated with skilled migrants.

Beyond micro studies focussing on differences in KSAOs, the human capital concept is also an important construct in macro-economic studies. Some articles use the notions of brain gain and brain drain to analyse the gain or loss of human capital by immigration flows between countries. This macro perspective considers the migration of skilled migrants a win for the host country, as qualified migrants fill the skills gap in certain occupations and transfer knowledge. Conversely, the migration of professionals is negative for the country of origin as it loses talented and productive workers (Bornat et al., 2011; Brugha et al., 2016; Ganguli, 2015; Herfs, 2014; Humphries et al., 2013; Liu et al., 2015; Silvanto et al., 2015; Stankovic et al., 2013). The migration of medical professionals is particularly discussed in terms of brain gain/drain. The points-based policy regimes adopted by countries such as Canada and Australia follow HCT and the brain gain/drain perspective. Such immigration policies and nation-branding campaigns target migrants possessing specific skill sets in high demand in the destination country, and assume that such migrants will fully integrate into the job market, thereby contributing to long-term economic growth, higher productivity and greater competitiveness (Covell et al., 2017; Hakak et al., 2010; Silvanto et al., 2015).

Empirical findings: Nevertheless, in empirical testing of HCT, only a few studies support the assumption that skilled immigrants' higher levels of human capital lead to better labour outcomes in the short- to mid-term. Contradictorily, many studies report the opposite. Although QIs, on average, are a privileged group with regard to their human capital, sociocultural and institutional factors shape their career outcomes differently (Ette et al., 2016). Despite a shortage of doctors in the Irish healthcare system, migrant doctors reported deskilling, brain waste and intention to emigrate (Humphries et al., 2013). Despite being skilled and selected based on their qualifications by the Australian immigration office, immigrant engineers and IT professionals face hurdles in the selection process and in integration once employed (Mahmud et al., 2014). Relatedly, a higher likelihood of skill underutilisation has been reported by IT and accounting professionals (Almeida and Fernando, 2017). Internationally educated nurses who had recently arrived in Canada were found to have high levels of human capital (knowledge, professional experience and language proficiency) but still had difficulty securing employment (Covell et al., 2017).

Human capital is not completely transferable between countries (Neubecker, 2014). Banerjee and Lee (2015) show that the national source of human capital (e.g. educational credentials from the host country) contributes to decreasing the earnings gap between QIs and locals.

Limitations: Some of the articles using micro-economic theories of HCT are less attentive to the complex effects of the socio-economic context of host societies on immigrants' career outcomes. Their cost-benefit perspective tends to overlook the importance of social networks and structural challenges (Harvey, 2012). For instance, Hakak et al. (2010) suggest that QIs' career success and satisfaction in host economies is strongly influenced by their ethnic origin.
Theories for studying qualified immigrants

1069 
EDI

41,7

HCT also has theoretical restrictions in capturing the attitudes and behaviours that migrants display as processes, rather than individual qualities.

Career capital theory (CCT)

Contribution to the research area: To enrich the HCT perspective, extensive research has investigated social capital and its effects on immigrants' career development (Lancee, 2012). For instance, Gericke et al. (2018) analyse the available types, uses and benefits of social capital with regard to refugees' accessing and integrating into the labour market. They found that vertical bridging social capital (i.e. organisations/institutions based on shared religion, nationality or ethnic background) is a valuable source for securing decent work, whereas horizontal bonding social capital (i.e. family members, friends and acquaintances in the host country) and independent job-searching methods often result in employment in low-skilled jobs. Similarly, Allen (2009) showed that access to co-ethnic social capital upon arrival decreased earnings for female refugees. Lubbers et al. (2020) review and classification of research on migrants' transnational social networks offers valuable insight.

A more exhaustive alternative to human capital and social capital is career capital theory (CCT; (DeFillippi and Arthur, 1994), also relabelled intelligent career theory (Arthur et al., 1995). CCT broadens the scope of human capital and provides a comprehensive typology of capitals needed to develop and achieve success in one's career. Adopting a resource-based perspective, DeFillippi and Arthur (1994) and Inkson and Arthur (2001) identified the main types of capital as knowing-why, knowing-how and knowing-whom. Knowing-why refers to the energy, sense of purpose, motivation and identification with the work that an individual brings to their career. Knowing-how, very similar to the notion of human capital, refers to the skills, expertise, and both tacit and explicit knowledge an individual accumulates. Knowingwhom, similar to the notion of social capital, refers to one's network of work-related connections, including not only supervisors and co-workers but also customers, suppliers, consultants, etc. (Inkson and Arthur, 2001). In the context of migration research, knowingwhy refers to knowing the reason for migration, the motivation for integration, and the expectations of the local labour market; knowing-how is the accredited skills and the knowledge of and familiarity with local business culture; and knowing-whom refers to developing a proper work and non-work network (Zikic, 2015).

Empirical findings: QIs are very likely to lose some of the human and social capitals crucial to their career advancement (Cooke et al., 2013). This can happen in various ways, such as non-accredited foreign degrees and certificates, lack of local work experience and ineffective communication due to language barriers. CCT conceives varied forms of career capital as dynamic factors, rather than static, fixed and given. As well as the stocked human capital brought from the country of origin, an immigrant may want to add to their human or social capital in the host country (Fang et al., 2009). Coping strategies include, for example, reeducation and participation in bridging programmes to familiarise oneself with the countryspecific professional culture or communication style (Fang et al., 2009). Regarding knowingwhy and motivation for migration, Cerdin et al. (2014) propose that migrants frame immigration in terms of expected gains versus losses. QIs who fear losing a lot by moving to the new country will have the lowest motivation to integrate, whereas those who believe they will substantially gain by so moving will be more motivated (and strive more) to integrate.

The role of organisations is very critical to QIs' career outcomes. Organisational characteristics such as size, resource availability, the global culture of the profession (e.g. IT) and having clients with a similar ethnic background to the migrant can all influence the employment of QIs, either unfavourably or favourably (Almeida et al., 2012). Organisational integration policies affect the motivations and, consequently, efforts of QIs to develop their career capital (Cerdin et al., 2014). Firms that embrace a level of diversity beyond race, age, 
and gender equality and that seek QI capitals as a source of competitive advantage increase the likelihood of QIs' employment and the full utilisation of their capitals (Zikic, 2015).

Limitations: Although CCT extends the narrow focus of human capital and considers other types of capital, including social connections and personal motivation, the researchers adopting this theory do not explicitly explore the significance of institutional environment on the development and deployment of career capital, particularly for QIs undergoing international career transitions.

\section{Bourdieu's theory of practice (BTP)}

Contribution to the research area: Several authors have found Bourdieu's theory of practice (Bourdieu, 1977; Bourdieu, 1986) to be useful for studying QIs (e.g. Al Ariss and Syed, 2011; Eggenhofer-Rehart et al., 2018; Fernando and Cohen, 2016; Liversage, 2009; Winterheller and Hirt, 2017). Like CCT, Bourdieu's theory (1986) considers other types of capital. However, beyond perceiving QIs as individuals possessing easily transferable capital, Bourdieu's theory of practice (BTP) argues that the home and host society value capital differently. This theory recognises the structural barriers that severely restrict legitimacy and use of capital in the host society. Another central notion is the agency of skilled immigrants in shaping their international work and lives (Al Ariss and Syed, 2011).

Rooted in sociology, the notions of habitus, field and capital are key elements of BTP (Bourdieu, 1986). According to Bourdieu, four forms of capital - economic, social, cultural and symbolic - determine the actions of a migrant in the new institutional framework of the host society. Migrants enter the host society with a specific worldview and set of dispositions (i.e. habitus). Habitus is a product of history (such as social class, family upbringing, and educational and work experiences in the home country) but can also be transformed. Through cultural encounters and socialisation, the habitus of the migrant transforms and they might change how they feel, act, talk, dress, hold their body, etc. BTP is essentially a relational theory that links migrants as agentic, reflexive and strategic actors with the embedded institutional contexts (i.e. field). In the context of international mobility, field refers to the socially constructed career environment in the new country, influenced by the national culture and labour market characteristics.

Bourdieu's theory elucidates the complex work experiences of skilled migrants embedded in a multi-layered context, encompassing, for example, migration policy, professional association policy, and individual characteristics and career strategies.

Empirical findings: Migrants might initially fail to achieve a desired career, due to devaluation of migrant capital in the host society (Joy et al., 2018) and inadequate job-search strategies in the new and different labour market (Eggenhofer-Rehart et al., 2018). After initially experiencing negative emotions, loss of identity and status, and a sense of out-ofplaceness, skilled migrants begin to learn the rules of the game in the country of migration and change their habitus accordingly. From an agentic view, Bourdieu proposes that skilled migrants mobilise the social, cultural and economic resources they possess and generate new forms of capital to sustain or improve their position within the host country's power structure (Al Ariss and Syed, 2011). Skilled migrants attempt to adjust to the new career field by accumulating career capital that is highly valued within the field (Winterheller and Hirt, 2017). Akkaymak (2017) showed that, in Canada, highly educated Turkish asylum seekers had considerably lower career attainment than Turkish skilled migrants. Besides having lower language proficiency, asylum seekers were also not permitted to apply for student loans, which prevented them accumulating Canadian institutionalised cultural capital.

According to Bourdieu, a new field necessitates change in habitus or capital. For instance, some migrants might leverage the capital connected to their country of origin (e.g. extensive knowledge of the culture, market and language) to create a new and rare culture-specific
Theories for studying qualified immigrants 
EDI

41,7

capital (Neville et al., 2014; Winterheller and Hirt, 2017). This type of culture-specific capital is valuable for a company in the host country that wants to do business in a migrant's home country. QIs might also become cultural brokers for other migrants and engage in activities such as translation or immigrant case work (Liversage, 2009). Sometimes, QIs might even try to change the rules of the game (Joy et al., 2018). From an agentic view, migrants might change the process of assessment and validation of their capital. For instance, McGuire and Lozada (2017) explored the reluctance of Filipino nurses in the UK to join unions and highlighted the activities of one particular nurse: a passionate advocate of non-EU workers' rights. She covertly acted as a Filipino trade union organiser to fight inequality in the workplace. In such cases, rather than relying on existing institutions, migrants strive to change the field and its rules.

Limitations: Bourdieu's theory has a macro perspective and focusses on the effects of the institutional framework and migrants' agency. It has less power to explain the role of organisations, such as diversity strategy, human resource (HR) processes and manager characteristics. Furthermore, BTP insufficiently emphasises the regulatory aspect of the institutional framework. Recent articles on the effects of regulatory standards and immigration policies include Fellini and Guetto (2019), Ozkan (2018), Tani (2020) and Devitt (2011).

\section{Sensemaking}

Contribution to the research area: Rooted in cognitive and social psychology, sensemaking (Weick, 1995) and critical sensemaking (CSM); (Helms Mills et al., 2010) provide a research lens to examine how immigrants make sense of their new environment. Sensemaking results from a shock, break in routine, or crisis, such as entering a new labour market, the interruption of routine understandings and practices regarding job-searching, networking and recruitment, or initial failure to adjust to the new life or integrate into the new labour market. The discrediting of their foreign experiences and the need to learn local business culture before gaining employment is a surprise for QIs (Zikic et al., 2010). Following such shocks or surprises, immigrants engage in sensemaking to not only determine what to do next but also resolve the anxiety and fear that may accompany the experience. CSM expands Weick's model by addressing the role of power and context and fusing structural and sociopsychological factors. CSM explains how the combination of individual psychological properties, organisational rules and the context in which organisations exist allow individuals to make sense of their environments and take action on a day-to-day basis (Helms Mills et al., 2010).

Sensemaking has a retrospective nature, and migrants mostly rely on the past to interpret their current situation. Retrospective sensemaking may, thus, have particular impact with respect to migrants' initial failure, as thinking-as-usual and expecting a set of actions to result in a specific outcome is not valuable in the new context. For example, the training that a skilled migrant has received previously or the negotiation skills they have used may not be applicable to their new job role and organisational setting. Sensemaking is grounded in identity construction in the context of social and ongoing interactions, and thus helps us understand how professional identity and other identity labels (e.g. newcomer, employed or unemployed, ethnic person, second-class) are produced, maintained and normalised in lived experience of QIs (Hilde and Mills, 2017). Sensemaking is not accurate but merely plausible. The understanding of post-migration events may not be the same among different migrant groups, and one event or situation may have various explanations. This reflects a situation where different meanings and coping strategies may emerge as plausible for different groups (Hilde and Mills, 2017). A similar approach is professional (re-)socialisation of immigrants (Neiterman and Bourgeault, 2015a, b), which considers the subtle aspects of work and language and the identity modification of QIs. 
Empirical findings: Although immigrants collect information about the destination country before migration and prepare themselves mentally for a change, they face challenges during the cultural transition phase. These can be related to missing family and friends, as well as coping with unfamiliar spaces, landscapes and ethnoscapes. Moreover, despite the belief that professional codes are universal, a new style of communication and different techniques and tools might form part of a myriad of social practices in a given cultural locality that the professional should adopt. After initial feelings of loneliness and alienating experiences, professionals begin to learn and understand the norms and practices through meaning reconstruction that eventually results in establishing equilibrium between self and society.

Malik et al. (2017) use four-phase transition cycle: preparation, encounter, adjustment and stabilisation. No matter how well a migrant has prepared for the new environment, novel experiences in terms of new work roles and cultural dissimilarities might bring stress, anxiety and new expectations. To adjust to these and pursue personal development, a migrant may adopt different strategies such as information seeking, relationship building, and formal and informal networking (Malik et al., 2017).

Aten et al. (2016) studied how a sample of Filipino engineers employed cognitive schemas (Weick, 1995) to overcome anxiety and uncertainty in the new context. Aten et al. (2016) identified three mobility frames that migrants use to make sense of career options and barriers: (1) the migrant mobility frame, which emphasises adaptation, high attachment to the host country, accepting invincible occupational barriers and taking available jobs, often leading to brain waste; (2) the mobile professional mobility frame, which emphasises opportunity exploitation, professional achievement and only taking professional jobs commensurate with one's skills level and (3) the migrant professional mobility frame, which lies in between and emphasises integration, acceptance that it takes time to overcome contextual barriers. This frame often leads to underutilisation of talent. Similarly, Zikic et al. (2010) found three types of sensemaking process and outcome: (1) embracing career orientation, characterised by QIs' motivation to succeed and take advantage of opportunities, their boundary-less and protean attitude, and proactive and self-directed decisions; (2) adaptive career orientation, characterised by maintaining aspiration to work in the previous occupation while taking survival jobs and participating in bridging programmes and (3) resisting career orientation, characterised by QIs' inability to exercise psychological mobility and discouragement by the challenges of the new context.

Limitations: Related research concerning QIs does not explicitly use the properties proposed by sensemaking (e.g. plausibility or identity construction). In addition, the decision to migrate and the period before the early shock (e.g. the antecedents of and sensemaking before migration) is outside the scope of CSM. The application of CSM in migration studies can be developed by focussing on resistance to diversity and inclusion in the host society and the social and psychological processes through which discriminatory practices spread and become acceptable.

\section{Social identity theory (SIT) and the similarity effect}

Social identity approach is now one of the most influential theories of group processes and intergroup relations worldwide.

Contribution to the research area: social identity theory (SIT) (Tajfel and Turner, 1986; Turner et al., 1987) is an influential social psychology perspective for explaining group processes. According to SIT, people tend to categorise others and themselves based on characteristics such as race, ethnicity, age and gender, and make "us vs them" or "in-group vs out-group" distinctions. Part of an individual's self-concept (i.e. attitudes, memories, behaviours and emotions) is social and formed by the groups to which the individual thinks they belong.
Theories for studying qualified immigrants

1073 
EDI

41,7

1074

This social self might occasionally overwhelm the idiosyncratic, individual qualities of the group's members and determine their attitudes, behaviours and emotions, such that a group member evaluates in-group members more positively than members of other groups (Hornsey, 2008; Sacco et al., 2003). Unlike theories focussed on immigrants' behaviours and perceptions, SIT essentially explains the non-inclusive behaviour of members of the host society. In particular, it is useful to explain subtle workplace discrimination.

Empirical findings: Some immigrants report pressure to mimic in order to access professional work: specifically, they need to adjust their professional identities to more closely resemble native professionals in their accents, way of dressing, assertiveness in meetings, etc. (Thomson and Jones, 2015).

SIT is well suited to explain discrimination towards minority ethnic groups during recruitment, performance management and promotion (Dietz et al., 2015). DelCampo et al. (2011) found perception of discrimination among both immigrant and native-born minorities. Candidates who resemble the majority natives in terms of ethnic background, religion, dress or accent are perceived as similar and in-group; otherwise, they are regarded as different and out-group (Almeida et al., 2015). Perceived similarity creates interpersonal attraction and facilitates both communication and prediction of the candidate's performance (Sacco et al., 2003). In-group/out-group distinction and subjective perception of similarity is also an appropriate framework to explain the negative stereotypes and ethnic biases against immigrants. Within an organisational context, the lack of perceived similarity and discrimination towards migrants lead to an ethnic penalty, entailing lower occupational attainment and wages and higher unemployment that cannot be explained by human capital and demographic characteristics (Rafferty, 2012). Aslund et al. (2014) showed that, on average, $6 \%$ of hires by native managers are immigrants while the corresponding figure is $21 \%$ for immigrant managers.

In a macro-level study, Annisette (2017) explains how three recognised professional accounting associations collaboratively aimed to separate accountants trained in the Canadian and British systems (i.e. "us") from foreign-trained accountants (i.e. "them", as undertrained, racialised minority accountants with credentials from a country in the "Global South"). Thus, categorising foreign-trained accountants and requiring them to train further normalises their inferior position in the landscape of accounting in Ontario, defined by the dominant Anglo-centric culture.

Limitations: Immigrants' role in diminishing subtle discrimination by interacting with and influencing the host society, along with the learning process of host society members and employers, is undermined in SIT.

\section{Intersectionality}

Contribution to the research area: Intersectionality is rooted in US-based feminist studies which focussed on the intersection of race and gender in the lives of black women (Crenshaw, 1991). Rather than treating gender, race and class as distinct social divisions on separate axes, intersectionality explores how oppression and resistance are constructed through amalgamation of such social and cultural divisions (e.g. the amalgamation of gender (male vs female), race (native vs ethnic) and class (immigrant or refugee vs local)). Intersectionality provides an alternative framework to analyse how power and inequality form based on the interplay of these divisions (Cole, 2009).

Empirical findings: Intersectionality has predominantly been used to study migrant women (Ali et al., 2017; Karlsen, 2012; Mulinari, 2015; Ressia et al., 2017b; Riano et al., 2015; Sang et al., 2013). Because the disadvantage discourse is often used in both migrant studies and women studies, it can be assumed that the intersection of gender and migration negatively affects working migrant women, such that they experience double disadvantage. 
However, Sang et al. (2013) report that the intersection of two marginalised identities (female and ethnic) does not necessarily result in a double disadvantage; rather, it sometimes offers opportunities. For instance, a professor stated that working closely with her cultural group in the UK provided opportunities for unique research publications and further academic career development.

Intersectionality can potentially be utilised to study the intersection of migration with age (e.g. Fernando et al., 2016), religion (Ali et al., 2017), class status and minority identity (Al Ariss et al., 2013), sexual orientation or disability.

Limitations: Intersectionality is primarily focussed on delineating the formation and maintenance of inequality, rather than elaborating on strategies for social change. It does not acknowledge how a class (i.e. immigrants) can be a source of power. Intersectionality also undermines the agency of migrants, whereas researchers have reported the efforts and ability of migrants to move forward and change. For instance, Murray and Ali (2016) reported Muslim women professionals successfully exercising their agency within the workplace "in response to western stereotypical organisational and societal norms and deep-seated patriarchal customs".

\section{Cultural identity transition (CIT) approach}

Contribution to the research area: Through this lens, immigration is perceived as a large-scale cultural change; accordingly, the migrant worker faces new societal and work cultures to which they need to adjust by negotiation between the home and host culture. This line of research is mainly based on Berry's (1997) immigrant acculturation strategies for explaining cultural transition. Berry's work is grounded in constructing a new identity and/or maintaining the previous identity. The intersection of these two identities creates four types of acculturation strategies: integration, assimilation, separation and marginalisation.

Empirical findings: Learning the language and developing socio-cultural relationships with natives increases the visibility of immigrants' ethnic identity. This visibility encourages immigrants to assess whether their identity fits the new context and, consequently, to engage in identity exploration, wherein they: (1) reinforce their ethnic identity; (2) adopt the host nation's dominant identity or (3) create a bicultural identity (Dheer and Lenartowicz, 2018).

Berry's (1997) typology provides a theoretical foundation for studying the antecedents and consequences of QIs' acculturation type. Researchers have identified several determinants of the type of acculturation strategy. Longer duration of stay, language proficiency and social support in the workplace help migrants to more comprehensively capture critical information and to perceive acceptance and inclusion, eventually leading to positive acculturation strategies (i.e. assimilation and integration) (Lu et al., 2011). Interdependent self-construal (seeing oneself as part of an encompassing social relationship and focussing on the connectedness and relatedness of individuals) is significantly associated with adopting integration strategy and avoiding marginalisation (Lu et al., 2016). The host country's collectivistic culture, collective workplace culture and organisational interventions to strengthen relationships among colleagues all increase the likelihood of adopting integration and decrease the likelihood of adopting marginalisation (Dheer and Lenartowicz, 2018; Lu et al., 2016). Krysa et al. (2017) use post-colonial analysis to investigate "the underlying assumptions embedded in the messages that are conveyed to teach and prepare immigrants for the Canadian workplace" (p. 483); they discover that neoliberalism, as the dominant paradigm, facilitates the assimilation of QIs, turning them into conforming members of a capitalist system.

Dheer and Lenartowicz (2018) assert that the type of acculturation strategy plays an important role in shaping a QI's career decisions. Separation likely leads to employment in the ethnic economy, either working for firms both owned and controlled by co-ethnic individuals
Theories for studying qualified immigrants

1075 
EDI

41,7

1076

who mainly employ people with common linguistic and cultural ties, or starting business ventures focussing primarily on the needs of ethnic consumers in the host society. Assimilation likely leads to mainstream employment: being part of the general workforce in the host country. Finally, integration likely leads to entrepreneurship, driven by opportunities in the host country's economy.

Limitations: CIT considers immigrants' experiences beyond their workplace and includes the interaction of QIs with the host society in general. However, its focus so far has been on the antecedents and outcomes of the transition, rather than the psychological processes of transition and identity reconstruction following immigration. In particular, the professional identity and its change process have been neglected.

\section{Career-centred approach}

Contribution to the field: Career development plays a significant role in QIs' decision to migrate and evaluation of their success or failure. In the context of rising international migration flows, we found extensive research focussing on new conceptualisations of career in an international context (Agullo and Egawa, 2009). Although careers take varied forms, an international career is seen as a work-related decision in the broad socio-economic context that has salient effect on the QI's life. Unlike the approaches discussed above, the careercentred approach is a loosely specified theoretical concept - an umbrella term - that combines a set of ideas about the QI's career.

Empirical findings: From a multi-level perspective, Baruch and Forstenlechner (2017) use Baruch et al. (2016) model to identify the determinants of highly skilled immigrants' motivation to migrate from or stay in peripheral countries (using the case of UAE). Multiple interconnected factors operate simultaneously at the individual, organisational and national levels, influencing QIs' motivation to consider employment in another country. Proposing the life-career integration model, Chen and Hong (2016) see profession and career choice as a way for QIs to place themselves within their broader society. Career is seen a critical element in the private and public identity of individuals. Similar to the sensemaking approach, the lifecareer integration model proposes that the career rebuilding experience happens alongside general life transition, significantly influencing migrants' sense of self-worth and identity.

Guerrero and Rothstein (2012) use elements of Kanfer et al.'s (2001) job-search model to investigate behaviours and cognitions that QIs can change to enhance their job-search outcomes. Job-search clarity (having clear search objectives and knowledge of job opportunities, how they plan to search, and when they will obtain a job) and job-search self-efficacy (confidence in one's ability to effectively accomplish job-search activities) are positively related to higher job-search intensity (more frequent and broader searching) and, ultimately, employment (Guerrero and Rothstein, 2012). Ressia et al. (2017a) revealed that skilled migrants concentrate on career self-management strategies, such as volunteering, finding any job to secure income and utilising social networks.

Al Ariss (2010) identifies four orientations or modes of engagement chosen by migrants to navigate within their new organisational and national structures and to cope with associated structural barriers. Maintenance refers to working around, rather than trying to alter, the recognised barriers (e.g. by changing name or hiding one's religion). In contrast, transformation, entrepreneurship and opt out reflect change entailing attempts to alter structural barriers or career capital (e.g. by pursuing new studies), taking additional risk in establishing a new business to overcome discrimination (e.g. opening a bookstore, instead of pursing an academic career) and operating outside exiting structures due to the pressure of barriers (e.g. deciding to be a housewife), respectively. Similarly, Murray and Ali (2016), referring to Bandura's human agency theory $(2001,2006)$, investigated the reactions and reflections of Muslim professional women on stressful workplace events, such as 
discriminatory behaviour, and categorised their responses. Casado and Caspersz (2016) and Morgan and Finniear (2009) use the psychological contract lens to analyse migrants' experiences and expectations in the workplace. They are perceived by employers to be better performers as they work longer and have higher motivation. However, migrants' lower levels of communication and language skills increase the possibility of error and limit their ability to cope with exceptional situations, such as unusual customer demands.
Theories for studying qualified immigrants

\section{Discussion: EDI experiences of QIs in the workplace}

This section goes beyond synthesising the existing literature by advancing prior inquiry. First, the identified theoretical approaches are combined to provide a comprehensive in-depth picture of the literature. To do so, the three anti-discriminatory approaches of EDI are used to map progress in explaining the discrimination experienced by QIs in the workplace. This addresses Research Question (1). Second, we supplement theoretical progress in the field by identifying new challenges facing societies and the research community. This addresses Research Question (2). Practical new challenges in the form of mechanisms and initiatives for combating workplace discrimination and improving EDI are presented. The suggested mechanisms and initiatives are based on insights from different theoretical approaches and international findings. Furthermore, a future research agenda is suggested, setting out the theoretical challenges confronting scholars, especially in the management and organisation field. The agenda outlines new or fused theoretical approaches that can provide better understanding of QIs' work experiences regarding EDI.

\section{Theoretical progress}

We use EDI to organise the QI literature. Based on reviews by Shore et al. (2011) and Oswick and Noon (2014), we distinctly define the three notions. Equality concerns equal opportunities in the labour market and denotes equal chance of entry into employment for QIs. Diversity entails the need to permit new demographic groups into the workplace, as well as providing opportunities for development, job enrichment and hierarchical promotion. Diversity is tied to demographic challenges (ageing population and the rapid rise in labour market entrants with different characteristics to dominant, white male workers) and focussed on improving performance and competitive advantage. Researchers distinguish two types of diversity. Surface-level diversity includes demographic characteristics (e.g. sex, age, race/ethnicity, disability); like equality initiatives, it is concerned with the fair treatment of these groups in the labour market and within organisations. However, deep-level diversity asserts a wider range of characteristics (e.g. attitudes, beliefs and values, cultural styles, functional backgrounds and cognitive styles), making the notion of diversity more distinctive than equality.

Inclusion as an anti-discriminatory approach is more concerned with missed opportunities than a business need. While diversity focusses on the demographic composition of the organisation and teams, inclusion focusses on employees' full participation and contribution to shaping strategy, work processes, management style and organisational culture by considering different knowledge and perspectives. Shore et al. (2011) propose the two dimensions of belongingness and uniqueness for perception of inclusion. For a QI to feel included, they should be treated as an insider in the work group (satisfying the need for belongingness) yet also be allowed/encouraged to retain uniqueness as their difference is considered an opportunity for both individual and organisational learning (confirming that their difference is valued).

Table 4 (column 1) outlines theoretical progress to date and explains the EDI challenges that QIs encounter in the workplace according to existing theories. This addresses Research Question (1). Interestingly, QIs sometimes experience advantages in the workplace. 


\section{EDI 41,7}

\section{8}

Diversity

Surface-level

diversity

(demographic)
Table 4.

Progress and new challenges regarding EDI experiences of QIs in the workplace
Theoretical progress

HCT, CCT: QIs experience limited access to employment opportunities and downgraded career outcomes since their foreign qualifications and work experiences are undervalued HCT, BTP: QIs in regulated professions perceive qualification recognition as a major structural barrier to accessing employment opportunities

CCT: Due to decreased social capital, QIs are less likely to be recruited to jobs vetted by informal networks. They would often have a survival job in sectors employing many of their ethnic group. On the contrary, sometimes, being bicultural and having knowledge of the home country culture and market increase opportunities to be employed as a cultural broker BTP: The field (particularly the regulatory aspect of the institutional framework) might systematically prevent some groups of QIs from utilising or accumulating career capital. Discrimination stems from institutional setting, e.g. not permitting asylum seekers to apply for study loans or not recognising foreign qualifications SIT: QIs experience an ethnic penalty (i.e. higher rate of unemployment, being over-educated and over-qualified for their roles, and receiving lower wages than locals) due to subtle discrimination based on their ethnicity, religion, traditional apparel, appearance and accent. Reasons for discrimination include gatekeepers considering QIs as a threat to local job applicants or the professional identity and negative stereotyping

Intersectionality: In many cases, the gender role of caregivers puts women ultimately in charge of settlement and caring for family and children, at the expense of their professional career. The gender role of the breadwinner puts men under psychological pressure when unable to find stable employment and financially provide for their family
Practical challenges for enhancing EDI

(1) Bridging courses and supplementary training should be co-created by employers and professional bodies and tailored to characteristics of immigrants' home educational system(s). Offering such courses to QIs reduces the qualification recognition challenge

(2) Local authorities should more actively seek collaboration of organisations, professional bodies, unions and civil society organisations to provide QIs with opportunities to engage with local organisations, professional networks and work culture. Survival jobs and learning the language can be combined with local work experience

(1) Organisations should recognise QIs as an emerging disadvantaged group and respond by: creating separate divisions or dedicating staff to deal solely with issues of nationality, diversity and inclusion; providing diversity training and reflection sessions; monitoring recruitment, pay and promotion with respect to immigrants; and extending the definition of discrimination to include covert forms of daily discrimination prevalent in the workplace, such as microaggressions 


\begin{tabular}{cc}
\hline Theoretical progress & Practical challenges for enhancing EDI \\
\hline
\end{tabular}

Deep-level diversity CSM: QIs experience verbal, attitudinal (cognitive)

Inclusion

Belongingness

Uniqueness and professional microaggressions (minor and unintentional degradations and putdowns in the form of sarcasm, stereotyping and scepticism) stemming from their ethnicity/nationality. This recurring, everyday experience contributes to the structures of oppression and marginalisation BTP: QIs' different habitus, including communication skills (e.g. during job interviews and day-to-day work interactions) and unfamiliarity with unwritten rules and norms, lead to higher unemployment and underemployment

CSM, CIT: Both explicit formal requirements and the subtler informal demands of employers and professional bodies force QIs to mimic the behaviours and attitudes of local professionals, who they must resemble to overcome structural barriers to employment, recognition and higher status. This mimicry is sometimes performed reluctantly and with frustration that cultural diversity is hypocritically valued in words but not in practice. QIs might unwillingly assimilate into the majority culture at the expense of retaining their original cultural/professional identity

CSM: QIs experience a constant struggle (continuously oscillating between feelings of foreignness or otherwise) while re-establishing their identity SIT, Intersectionality: Social categorising of QIs as out-group due to their different ethnicity, race and religion is a common phenomenon CIT: Language proficiency and social support at work (supportive supervisor and co-workers) are related to identifying with the host country's cultural identity (higher belongingness) Intersectionality: Being disadvantaged across multiple groups (e.g. based on ethnicity, gender, religion, age) does not necessarily lead summatively to multiple jeopardy. Surprisingly, being an outsider in several domains can give QIs unique career capital
(1) With negative images of immigrants abundant in media and politics (e.g. unemployed people in need regarded as a burden on the welfare system and associated with unregulated work), QIs should actively communicate their contribution to society and the economy (e.g. addressing skills shortages, increasing entrepreneurship and innovation, enriching cultural life)

(2) Labour market integration initiatives should include an educational module on the labour market and working culture. Organisations can contribute to this by providing internship opportunities and communicating to QIs the norms and behavioural patterns of the working culture and effective local techniques for jobseeking and networking

(1) Organisations should assign trained mentors to QIs. These mentors should act as cultural and technical brokers and interpreters to assist QIs to acculturate

(2) Organisations should provide opportunities for immigrants to be involved in diversity management and recruitment processes

(1) Organisational learning should be part of the rationale for diversity and inclusion. Diversity and inclusion should be reflected in related processes, such as CSR, strategy, sustainability and ethical codes of conduct
Theories for studying qualified immigrants

1079

Note(s): HCT: Human capital theory; CCT: Career capital theory; BTP: Bourdieu's theory of practice; SIT: Social identity theory; CSM: Critical sensemaking; CIT: Cultural identity transition

Table 4 
EDI

41,7

1080
For instance, the bicultural identity of QIs and their familiarity with the home culture and market provide opportunities to be employed as cultural brokers.

\section{New challenges}

New challenges are divided into two categories: practical and theoretical.

The practical new challenges aim to enhance EDI and include initiatives and strategies that could be considered by social actors to make a difference in the workplace and labour market. Higher levels of communication and collaboration are needed among immigrants, organisations, civil society organisations, and national, regional and local institutions to consider different perspectives. In particular, employers should be more involved in policymaking. Their concern regarding QIs' acculturation to the local work culture, communication style and behavioural norms should be incorporated in labour market integration initiatives. Organisations should also actively participate in these initiatives by offering internships and mentorships to newly arrived QIs. Civil society organisations, such as unions, industry associations and non-governmental organisations, can initiate and direct the communication and collaboration among different levels. Initiatives and strategies for enhancing EDI are presented in Table 4 (column 2).

The theoretical challenges form a future research agenda. We identified the theoretical grounds used in the literature to study QIs. As Table 3 shows, five streams are based on theories borrowed from disciplines other than management and organisation studies, such as sociology, psychology and economics. The remaining three theoretical approaches are developed by management scholars; however, except for a few studies adopting the careercentred approach, the models and frameworks are not developed specifically for studying immigrants. Also, as our classification of theoretical approaches into process and content theories indicates, none of the approaches comprehensively includes the antecedents, process and consequences of migration. Accordingly, developing a comprehensive theoretical framework specifically for QI studies is an urgent necessity.

As a path towards such a framework for studying QIs' EDI experiences in the workplace, we propose several theoretical considerations for future research. Some elaborate on suggestions made by other researchers, some fuse identified theoretical approaches to enhance explanatory power and some are new theoretical approaches for extending current thinking regarding the workplace EDI experiences of QIs.

(1) Relational/multi-level approach: The relational perspective proposes that QIs' experiences result from interrelated and interdependent multi-level challenges faced by QIs in the host labour market (Al Ariss and Syed, 2011; Syed, 2008). This perspective particularly emphasises the micro-level individual agency of migrants in shaping their experiences, as well as the meso-level organisational and macro-level professional and institutional influences that shape the reality QIs experience (Al Ariss and Syed, 2011). Specifically, the role of meso-level factors is less studied, with the following critical missing elements needing further investigation: the attitudes and characteristics of hiring managers; diversity strategies; HR practices; unions as proponents of EDI in the workplace; and the initiatives of civil society organisations and non-governmental organisations in assisting migrants to integrate into the host society by offering volunteer jobs, language training, psychological support and informal contacts. At the macro level, we suggest using the institutional theory and its three pillars.

(2) Strategic human resource view: QIs build a talent pool in the host country, and through management and utilisation of their talents, the national economy and organisations would gain enhanced competitive advantage (Zikic, 2015). QIs have high potential to influence organisational and societal outcomes. The prevalent 
discourse of the lack and deficit approach often frames immigrants as a problem; a group lacking necessary personal qualities in term of capital and language, dependent on assistance from the host society and unable to be integrated (Horner and Weber, 2011; Ponzoni et al., 2017). Adopting a strategic human resource management (SHRM) perspective, more studies are needed to scrutinise migrants' value for organisations in the host society and to identify the rationales of organisations when hiring QIs. These rationales might include creating an optimal mix of competencies, cost-efficient allocation of labour and legitimacy gains for different stakeholders (Ortlieb et al., 2014). The SHRM approach might even reveal how immigrants can influence the strategic course of an organisation in a bottom-up manner, for instance, through entering a new market due to social capital of immigrants in their country of origin. Specifically, the notion of inclusion is in line with SHRM.

(3) Agency-institution play: Exercising agency and its effects on career consequences are discussed explicitly in some theoretical approaches, such as BTP. Institutional frameworks have also been discussed mainly in terms of their objective or subtle career barriers in critical sensemaking, BTP and SIT. However, it is necessary to elaborate on the dynamic interaction of agency-institution, how the institutional framework encourages or restricts QIs' agency in their career trajectory, and specifically how QIs can exercise their agency to change the institutional framework.

(4) Identity-capital play: Some theoretical approaches, such as CCT or BTP, mainly try to explain how QIs rebuild their capital in the new environment, while others, such as CSM or CIT, focus mainly on changes in professional identity. However, QIs often use a compromise strategy by rebuilding their career capital and simultaneously adjusting professional identity. Some interesting questions to pose include: Under what conditions does a QI's change of professional identity (e.g. becoming an entrepreneur or entirely changing their occupation) lead to a better career trajectory? Under what conditions does accumulation of career capital (e.g. re-education before entering the job market) lead to a better career trajectory? What are the long-term effects of changing professional identity or cultural identity on a QI's career success, job satisfaction and life satisfaction?

(5) Host-immigrant play (fusing SIT and CSM): Proper fusion of theories can lead to higher explanatory power regarding QIs' work experiences by addressing the limitations of individual theories. Tatli and Özbilgin's (2012) work on combining BTP and intersectionality is a good example of such an effort. To overcome the predominant etic approach in researching EDI in the workplace (e.g. static, fixed and predetermined notions of difference or Western bias), they propose combining intersectionality and BTP to form an emic approach that starts by empirically identifying situated, context-specific categories of diversity. BTP is then used to "grasp the complex way in which privilege and disadvantage work across the lines of difference" (Tatli and Ozbilgin, 2012). As another example, we propose fusing CSM and SIT to relate immigrants' and local perspectives. Both theories have identity construction as a central concept for understanding the process of self-construction. CSM is used to explain how immigrants respond to the questions "Who am I?" and "How should I act?". SIT also deals with self-construction, but its identity construction is based on group membership and rests on the concept of otherness. SIT is used to explain how members of the host society respond to the questions "Who am I and who am I not?" and "How am I different and from whom? How am I similar and with whom?" (Holck et al., 2016).
Theories for studying qualified immigrants

1081 
EDI

41,7

1082

While a few studies have attempted to explain the process of re-establishing immigrant identity through communication and negotiation with local people and institutions, we are not aware of any study on re-establishing the host society's social identity based on interaction with immigrants. Host societies and organisations must learn to change their attitude, perceptions and behaviours towards immigrants, especially with respect to their integration. Management and organisation scholars could specifically analyse the sensemaking process of gatekeepers such as hiring managers and decision-makers at professional bodies, as well as co-workers and customers in the workplace.

This is a timely topic with important practical implications for investigating how host society members make sense of immigration and the changes that immigrants cause in the society. In recent years, migration has become a challenging political agenda item for almost all countries in the "Global North". For instance, the recent influx of refugees into Europe has intensified social and political concern about immigrants. Fear that the current levels and structure of migration are unsustainable is influencing backlashes against globalisation, such as Brexit, the America First policy and the rise of right-wing parties.

\section{Conclusion}

We identified eight theoretical grounds used in the literature to delineate the process of migration and effects on the careers and lives of QIs. To summarise the theoretical progress, we then presented state-of-the-art understanding of QIs' EDI experiences in the workplace. Finally, to extend current thinking, we discussed new challenges facing societies in terms of initiatives for enhancing EDI in the workplace and labour market and identified future research directions.

Due to its focus on theory development, this study excluded empirical papers with no theoretical foundation. This research limitation should be addressed by a systematic review of empirical literature. We also only considered management and organisation literature. There are numerous other research fields, such as sociology, public policy, economics, geography and migration studies that can provide researchers with further insights and guidance.

To develop a holistic understanding of QIs' work experiences, a framework with a multilevel approach and including the strategic human resource view, agency-institution play, identity-capital play and host-immigrant play is needed. It should also focus more on changes, learning processes and the role of organisations, hiring managers and labour market intermediaries. Developing such a framework would facilitate gaining a comprehensive view of QIs' work experiences and could add value to HR and employment research. We hope our review is a first step towards developing the theoretical framework for studying QIs in the workplace.

\section{References}

Agullo, B. and Egawa, M. (2009), "International careers of Indian workers in Tokyo: examination and future directions", Career Development International, Vol. 14 No. 2, pp. 148-168.

Akkaymak, G. (2017), "A Bourdieuian analysis of job search experiences of immigrants in Canada”, Journal of International Migration and Integration, Vol. 18 No. 2, pp. 657-674.

$\mathrm{Al}$ Ariss, A. (2010), "Modes of engagement: migration, self-initiated expatriation, and career development", Career Development International, Vol. 15 No. 4, pp. 338-358.

$\mathrm{Al}$ Ariss, A. and Syed, J. (2011), "Capital mobilization of skilled migrants: a relational perspective", British Journal of Management, Vol. 22 No. 2, pp. 286-304.

Al Ariss, A., Vassilopoulou, J., Özbilgin, M.F. and Game, A. (2013), "Understanding career experiences of skilled minority ethnic workers in France and Germany", The International Journal of Human Resource Management, Vol. 24 No. 6, pp. 1236-1256. 
Ali, F., Malik, A., Pereira, V. and Al Ariss, A. (2017), "A relational understanding of work-life balance of Muslim migrant women in the west: future research agenda", International Journal of Human Resource Management, Vol. 28 No. 8, pp. 1163-1181.

Allen, R. (2009), "Benefit or burden? Social capital, gender, and the economic adaptation of refugees", International Migration Review, Vol. 43 No. 2, pp. 332-365.

Allmen, P.V., Leeds, M. and Malakorn, J. (2015), "Victims or beneficiaries?: Wage premia and national origin in the national hockey league", Journal of Sport Management, Vol. 29 No. 6, pp. 633-641.

Almeida, S. and Fernando, M. (2017), "Making the cut: occupation-specific factors influencing employers in their recruitment and selection of immigrant professionals in the information technology and accounting occupations in regional Australia", International Journal of Human Resource Management, Vol. 28 No. 6, pp. 880-912.

Almeida, S., Fernando, M. and Sheridan, A. (2012), "Revealing the screening: organisational factors influencing the recruitment of immigrant professionals", International Journal of Human Resource Management, Vol. 23 No. 9, pp. 1950-1965.

Almeida, S., Fernando, M., Hannif, Z. and Dharmage, S.C. (2015), "Fitting the mould: the role of employer perceptions in immigrant recruitment decision-making", International Journal of Human Resource Management, Vol. 26 No. 22, pp. 2811-2832.

Alvarado, M. and Ricard, R.J. (2013), "Developmental assets and ethnic identity as predictors of thriving in hispanic adolescents", Hispanic Journal of Behavioral Sciences, Vol. 35 No. 4, pp. 510-523.

Amuedo-Dorantes, C. and Sevilla, A. (2014), "Low-skilled immigration and parenting investments of college-educated mothers in the United States evidence from time-use data", Journal of Human Resources, Vol. 49 No. 3, pp. 509-539.

Annisette, M. (2017), "Discourse of the professions: the making, normalizing and taming of Ontario's foreign-trained accountant”, Accounting Organizations and Society, Vol. 60, pp. 37-61.

Arthur, M.B., Claman, P.H. and DeFillippi, R.J. (1995), "Intelligent enterprise, intelligent careers", Academy of Management Perspectives, Vol. 9 No. 4, pp. 7-20.

Asali, M. (2017), "The effects of (different types of) immigrants on labor market outcomes of (different groups of) natives", International Journal of Manpower, Vol. 38 No. 3, pp. 338-353.

Aslund, O., Hensvik, L. and Skans, O.N. (2014), "Seeking similarity: how immigrants and natives manage in the labor market", Journal of Labor Economics, Vol. 32 No. 3, pp. 405-441.

Aten, K., Nardon, L. and Isabelle, D. (2016), "Making sense of foreign context: skilled migrant's perceptions of contextual barriers and career options", International Journal of Cross Cultural Management, Vol. 16 No. 2, pp. 191-214.

Bahn, S. (2015), "Managing the well-being of temporary skilled migrants", International Journal of Human Resource Management, Vol. 26 No. 16, pp. 2102-2120.

Bandura, A. (2001), "Social cognitive theory: an agentic perspective", Annual Review of Psychology, Vol. 52 No. 1, pp. 1-26.

Bandura, A. (2006), "Toward a psychology of human agency", Perspectives on Psychological Science, Vol. 1 No. 2, pp. 164-80.

Banerjee, R. and Lee, B.Y. (2015), "Decreasing the recent immigrant earnings gap: the impact of Canadian credential attainment", International Migration, Vol. 53 No. 2, pp. 205-218.

Baruch, Y. and Forstenlechner, I. (2017), "Global careers in the Arabian Gulf understanding motives for self-initiated expatriation of the highly skilled, globally mobile professionals", Career Development International, Vol. 22 No. 1, pp. 3-22.

Baruch, Y., Dickmann, M., Altman, Y. and Bournois, F. (2013), "Exploring international work: types and dimensions of global careers", International Journal of Human Resource Management, Vol. 24 No. 12, pp. 2369-2393.
Theories for studying qualified immigrants

1083 
EDI

41,7

Baruch, Y., Altman, Y. and Tung, R.L. (2016), "Career mobility in a global era: advances in managing expatriation and repatriation", Academy of Management Annals, Vol. 10 No. 1, pp. 841-889.

Baxter-Reid, H. (2016), "Buying into the 'good worker' rhetoric or being as good as they need to be? The effort bargaining process of new migrant workers”, Human Resource Management Journal, Vol. 26 No. 3, pp. 337-350.

Baycan, T., Sahin, M. and Nijkamp, P. (2012), "The urban growth potential of second-generation migrant entrepreneurs: a sectoral study on Amsterdam”, International Business Review, Vol. 21 No. 6, pp. 971-986.

Becker, G.S. (1962), "Investment in human capital: a theoretical analysis", Journal of Political Economy, Vol. 70 No. 5, pp. 9-49, Part 2.

Behrenz, L., Delander, L. and Mansson, J. (2016), "Is starting a business a sustainable way out of unemployment? Treatment effects of the Swedish start-up subsidy", Journal of Labor Research, Vol. 37 No. 4, pp. 389-411.

Bell, M.P., Kwesiga, E.N. and Berry, D.P. (2010), “Immigrants the new 'invisible men and women' in diversity research", Journal of Managerial Psychology, Vol. 25 No. 2, pp. 177-188.

Bernal, D.R., Herbst, R.B., Lewis, B.L. and Feibelman, J. (2017), "Ethical care for vulnerable populations receiving psychotropic treatment", Ethics and Behavior, Vol. 27 No. 7, pp. 582-598.

Berry, J.W. (1997), "Immigration, acculturation, and adaptation", Applied Psychology, Vol. 46 No. 1 , pp. 5-34.

Bimrose, J. and McNair, S. (2011), “Career support for migrants: transformation or adaptation?”, Journal of Vocational Behavior, Vol. 78 No. 3, pp. 325-333.

Binggeli, S., Dietz, J. and Krings, F. (2013), "Immigrants: a forgotten minority", Industrial and Organizational Psychology-Perspectives on Science and Practice, Vol. 6 No. 1, pp. 107-113.

Bohn, S. and Owens, E.G. (2012), "Immigration and informal labor", Industrial Relations, Vol. 51 No. 4, pp. 845-873.

Bornat, J., Henry, L. and Raghuram, P. (2011), "The making of careers, the making of a discipline: Luck and chance in migrant careers in geriatric medicine", Journal of Vocational Behavior, Vol. 78 No. 3, pp. 342-350.

Bourdieu, P. (1977), Outline of a Theory of Practice (Translated by R. Nice), Cambridge University Press, Cambridge.

Bourdieu, P. (1986), The Forms of Capital Handbook of Theory and Research for the Sociology of Education, pp. 241-258, R.(1974). The Power Broker: Robert Moses and the Fall of New York, Greenwood Press, Westport.

Brugha, R., McAleese, S., Dicker, P., Tyrrell, E., Thomas, S., Normand, C. and Humphries, N. (2016), "Passing through-reasons why migrant doctors in Ireland plan to stay, return home or migrate onwards to new destination countries", Human Resources for Health, Vol. 14, Suppl 1, p. 35.

Burke, R.J. and Ng, E. (2006), "The changing nature of work and organizations: implications for human resource management”, Human Resource Management Review, Vol. 16 No. 2, pp. 86-94.

Busch, C., Koch, T., Clasen, J., Winkler, E. and Vowinkel, J. (2017), "Evaluation of an organizational health intervention for low-skilled workers and immigrants", Human Relations, Vol. 70 No. 8, pp. 994-1016.

Casado, R. and Caspersz, D. (2016), "From 'opportunity'to 'insecurity': the psychological contract of highly skilled immigrants in Western Australia", Labour and Industry: A Journal of the Social and Economic Relations of Work, Vol. 26 No. 3, pp. 190-202.

Cerdin, J.L. and Selmer, J. (2013), "Who is a self-initiated expatriate? Towards conceptual clarity of a common notion", The International Journal of Human Resource Management, Vol. 25 No. 9, pp. 1281-1301.

Cerdin, J.L., Dine, M.A. and Brewster, C. (2014), “Qualified immigrants' success: Exploring the motivation to migrate and to integrate", Journal of International Business Studies, Vol. 45 No. 2, pp. 151-168. 
Chen, C.P. and Hong, J.W.L. (2016), "Career development of Chinese Canadian professional immigrants", Career Development Quarterly, Vol. 64 No. 3, pp. 272-286.

Cohen, L., Arnold, J. and O'Neill, M. (2011), "Migration: vocational perspectives on a complex and diverse transition", Journal of Vocational Behavior, Vol. 78 No. 3, pp. 321-324.

Cole, E.R. (2009), "Intersectionality and research in psychology", American Psychologist, Vol. 64 No. 3, p. 170.

Cooke, F.L., Zhang, J.Y. and Wang, J. (2013), "Chinese professional immigrants in Australia: a gendered pattern in (re)building their careers", International Journal of Human Resource Management, Vol. 24 No. 13, pp. 2628-2645.

Covell, C.L., Primeau, M.D., Kilpatrick, K. and St-Pierre, I. (2017), "Internationally educated nurses in Canada: predictors of workforce integration”, Human Resources for Health, Vol. 15 No. 1, p. 26.

Crenshaw, K. (1991), "Mapping the margins: intersectionality, identity politics, and violence against women of color", Stanford Law Review, Vol. 43 No. 6, pp. 1241-1299.

DeFillippi, R.J. and Arthur, M.B. (1994), “The boundaryless career: a competency-based perspective”, Journal of Organizational Behavior, Vol. 15 No. 4, pp. 307-324.

DelCampo, R.G., Jacobson, K.J.L., Van Buren, H.J. and Blancero, D.M. (2011), “Comparing immigrant and US born Hispanic business professionals Insights on discrimination", Cross Cultural Management-an International Journal, Vol. 18 No. 3, pp. 327-350.

Devitt, C. (2011), "Varieties of capitalism, variation in labour immigration", Journal of Ethnic and Migration Studies, Vol. 37 No. 4, pp. 579-596.

Dheer, R.J.S. and Lenartowicz, T. (2018), "Career decisions of immigrants: role of identity and social embeddedness”, Human Resource Management Review, Vol. 28 No. 2, pp. 144-163.

Dietz, J., Joshi, C., Esses, V.M., Hamilton, L.K. and Gabarrot, F. (2015), “The skill paradox: explaining and reducing employment discrimination against skilled immigrants", International Journal of Human Resource Management, Vol. 26 No. 10, pp. 1318-1334.

Doherty, N., Doherty, N., Richardson, J. and Thorn, K. (2013), "Self-initiated expatriation”, Career Development International, Vol. 18 No. 1, pp. 6-11.

Eggenhofer-Rehart, P.M., Latzke, M., Pernkopf, K., Zellhofer, D., Mayrhofer, W. and Steyrer, J. (2018), "Refugees' career capital welcome? Afghan and Syrian refugee job seekers in Austria", Journal of Vocational Behavior, Vol. 105, pp. 31-45.

Elrick, J. (2016), "Screening, skills and cultural fit: theorizing immigrant skill utilization from an organizational perspective", Journal of International Migration and Integration, Vol. 17 No. 3, pp. 801-817.

Emilsson, H. (2015), "A national turn of local integration policy: multi-level governance dynamics in Denmark and Sweden”, Comparative Migration Studies, Vol. 3 No. 1, p. 7.

Ette, A., Heß, B. and Sauer, L. (2016), "Tackling Germany's demographic skills shortage: permanent settlement intentions of the recent wave of labour migrants from non-European countries", Journal of International Migration and Integration, Vol. 17 No. 2, pp. 429-448.

Fang, T., Zikic, J. and Novicevic, M.M. (2009), "Career success of immigrant professionals: stock and flow of their career capital”, International Journal of Manpower, Vol. 30 No. 5, pp. 472-488.

Farcas, D. and Goncalves, M. (2017), "Motivations and cross-cultural adaptation of self-initiated expatriates, assigned expatriates, and immigrant workers: the case of Portuguese migrant workers in the United Kingdom”, Journal of Cross-Cultural Psychology, Vol. 48 No. 7, pp. 1028-1051.

Fellini, I. and Guetto, R. (2019), "A 'U-shaped' pattern of immigrants' occupational careers? A comparative analysis of Italy, Spain, and France”, International Migration Review, Vol. 53 No. 1, pp. 26-58.

Fernando, W.D.A. and Cohen, L. (2016), "Exploring career advantages of highly skilled migrants: a study of Indian academics in the UK", International Journal of Human Resource Management, Vol. 27 No. 12, pp. 1277-1298.
Theories for studying qualified immigrants 
EDI

41,7

1086

Fernando, M., Almeida, S. and Dharmage, S.C. (2016), "Employer perceptions of migrant candidates' suitability: the influence of decision-maker and organisational characteristics", Asia Pacific Journal of Human Resources, Vol. 54 No. 4, pp. 445-464.

Flynn, C.B., Feild, H.S. and Bedeian, A.G. (2011), "'Life could be a dream' what US-based management $\mathrm{PhD}$ students desire in an initial academic appointment", Career Development International, Vol. 16 Nos 4-5, pp. 316-341.

Ford, M. and Kawashima, K. (2016), "Regulatory approaches to managing skilled migration: Indonesian nurses in Japan”, Economic and Labour Relations Review, Vol. 27 No. 2, pp. 231-247.

Friberg, J.H., Arnholtz, J., Eldring, L., Hansen, N.W. and Thorarins, F. (2014), "Nordic labour market institutions and new migrant workers: polish migrants in Oslo, Copenhagen and Reykjavik", European Journal of Industrial Relations, Vol. 20 No. 1, pp. 37-53.

Ganguli, I. (2015), "Immigration and ideas: what did Russian scientists "bring' to the United States?", Journal of Labor Economics, Vol. 33 No. S1, pp. S257-S288.

Gericke, D., Burmeister, A., Löwe, J., Deller, J. and Pundt, L. (2018), "How do refugees use their social capital for successful labor market integration? An exploratory analysis in Germany", Journal of Vocational Behavior, Vol. 105, pp. 46-61.

Guerrero, L. and Rothstein, M.G. (2012), "Antecedents of underemployment: job search of skilled immigrants in Canada", Applied Psychology-An International Review-Psychologie AppliqueeRevue Internationale, Vol. 61 No. 2, pp. 323-346.

Hagan, J., Lowe, N. and Quingla, C. (2011), "Skills on the move: rethinking the relationship between human capital and immigrant economic mobility", Work and Occupations, Vol. 38 No. 2, pp. 149-178.

Haines, V.Y. III, Saba, T. and Choquette, E. (2008), "Intrinsic motivation for an international assignment", International Journal of Manpower, Vol. 29 No. 5, pp. 443-461.

Hajro, A., Stahl, G.K., Clegg, C.C. and Lazarova, M.B. (2019), "Acculturation, coping, and integration success of international skilled migrants: an integrative review and multilevel framework", Human Resource Management Journal, Vol. 29 No. 3, pp. 338-352.

Hakak, L.T., Holzinger, I. and Zikic, J. (2010), "Barriers and paths to success Latin American MBAs' views of employment in Canada", Journal of Managerial Psychology, Vol. 25 No. 2, pp. 159-176.

Harvey, W.S. (2012), "Labour market experiences of skilled British migrants in Vancouver", Employee Relations, Vol. 34 No. 6, pp. 658-669.

Helms Mills, J., Thurlow, A. and Mills, A.J. (2010), "Making sense of sensemaking: the critical sensemaking approach", Qualitative Research in Organizations and Management: An International Journal, Vol. 5 No. 2, pp. 182-195.

Herfs, P.G. (2014), "Aspects of medical migration with particular reference to the United Kingdom and The Netherlands", Human Resources for Health, Vol. 12, p. 59.

Hilde, R.K. and Mills, A. (2017), "Making sense from the in-between state immigrants' identity work and the micro-processes of resistance", Equality Diversity and Inclusion, Vol. 36 No. 2, pp. 150-164.

Hirt, C., Ortlieb, R., Winterheller, J., Besic, A. and Scheff, J. (2017), "Developing international talents: how organisational and individual perspectives interact", European Journal of Training and Development, Vol. 41 No. 7, pp. 610-627.

Holck, L., Muhr, S.L. and Villeseche, F. (2016), "Identity, diversity and diversity management: on theoretical connections, assumptions and implications for practice", Equality, Diversity and Inclusion: An International Journal, Vol. 35 No. 1, pp. 48-64.

Hopkins, B., Dawson, C. and Veliziotis, M. (2016), "Absence management of migrant agency workers in the food manufacturing sector", International Journal of Human Resource Management, Vol. 27 No. 10, pp. 1082-1100. 
Horner, K. and Weber, J.J. (2011), "Not playing the game: shifting patterns in the discourse of integration", Journal of Language and Politics, Vol. 10 No. 2, pp. 139-159.

Hornsey, M.J. (2008), "Social identity theory and self-categorization theory: a historical review", Social and Personality Psychology Compass, Vol. 2 No. 1, pp. 204-222.

Horverak, J.G., Sandal, G.M., Bye, H.H. and Pallesen, S. (2013), "Managers' selection preferences: the role of prejudice and multicultural personality traits in the assessment of native and immigrant job candidates", European Review of Applied Psychology-Revue Europeenne De Psychologie Appliquee, Vol. 63 No. 5, pp. 267-275.

Humphries, N., Tyrrell, E., McAleese, S., Bidwell, P., Thomas, S., Normand, C. and Brugha, R. (2013), "A cycle of brain gain, waste and drain-a qualitative study of non-EU migrant doctors in Ireland", Human Resources for Health, Vol. 11, p. 63.

Inkson, K. and Arthur, M.B. (2001), "How to be a successful career capitalist", Organizational Dynamics, Vol. 30 No. 1, pp. 48-61.

Joy, S., Game, A.M. and Toshniwal, I.G. (2018), "Applying Bourdieu's capital-field-habitus framework to migrant careers: taking stock and adding a transnational perspective", The International Journal of Human Resource Management, Vol. 31 No. 20, pp. 1-24.

Kanfer, R., Wanberg, C.R. and Kantrowitz, T.M. (2001), "Job search and employment: a personalitymotivational analysis and meta-analytic review", Journal of Applied Psychology, Vol. 86 No. 5, p. 837.

Kao, R.H. (2017), “Task-oriented work characteristics, self-efficacy, and service-oriented organizational citizenship behavior a cross-level analysis of the moderating effect of social work characteristics and collective efficacy", Personnel Review, Vol. 46 No. 4, pp. 718-739.

Karlsen, H. (2012), "Gender and ethnic differences in occupational positions and earnings among nurses and engineers in Norway: identical educational choices, unequal outcomes", Work Employment and Society, Vol. 26 No. 2, pp. 278-295.

Krysa, I.M., Mills, A. and Barragan, S. (2017), "Canadian immigrant guidelines on how to become productive members of society A postcolonial analysis", Equality Diversity and Inclusion, Vol. 36 No. 6, pp. 482-500.

Lancee, B. (2012), Immigrant Performance in the Labour Market: Bonding and Bridging Social Capital, Amsterdam University Press, Amsterdam.

Li, C., Li, H.J. and Niu, J.H. (2016), "Intercultural stressors of Chinese immigrant students: voices of Chinese-American mental health professionals", Asian American Journal of Psychology, Vol. 7 No. 1, pp. 64-73.

Lima, J. and Martins, A. (2012), "Mobility among Latin American migrants the case of Bolivians in Sao Paulo and Brazilians in london", Employee Relations, Vol. 34 No. 6, pp. 594-612.

Liu, X.H., Gao, L., Lu, J.Y. and Wei, Y.Q. (2015), "The role of highly skilled migrants in the process of inter-firm knowledge transfer across borders", Journal of World Business, Vol. 50 No. 1, pp. $56-68$.

Liversage, A. (2009), "Vital conjunctures, shifting horizons: high-skilled female immigrants looking for work", Work Employment and Society, Vol. 23 No. 1, pp. 120-141.

Lohaus, D. and Habermann, W. (2019), "Presenteeism: a review and research directions", Human Resource Management Review, Vol. 29 No. 1, pp. 43-58.

Lu, Y., Cheng, H. and Zhang, J. (2011), Research on Citizenization Route of the New Generation Migrant Workers in Housing Industry, Hong Kong Polytechnic Univ, Kowloon.

Lu, Y., Samaratunge, R. and Hartel, C.E.J. (2016), "Predictors of acculturation attitudes among professional Chinese immigrants in the Australian workplace", Journal of Management and Organization, Vol. 22 No. 1, pp. 49-67.

Lubbers, M.J., Verdery, A.M. and Molina, J.L. (2020), "Social networks and transnational social fields: a review of quantitative and mixed-methods approaches", International Migration Review, Vol. 54 No. 1, 0197918318812343.
Theories for studying qualified immigrants 
EDI

41,7

1088

Mahmud, S., Alam, Q. and Hartel, C. (2014), "Mismatches in skills and attributes of immigrants and problems with workplace integration: a study of IT and engineering professionals in Australia", Human Resource Management Journal, Vol. 24 No. 3, pp. 339-354.

Malik, A.R., Manroop, L. and Singh, P. (2017), "Self-initiated international career transition: a qualitative case study of Pakistani immigrants to Canada", European Business Review, Vol. 29 No. 5, pp. 584-602.

Manroop, L., Boekhorst, J.A. and Harrison, J.A. (2013), "The influence of cross-cultural differences on job interview selection decisions", International Journal of Human Resource Management, Vol. 24 No. 18, pp. 3512-3533.

Marfleet, P. and Blustein, D.L. (2011), "Needed not wanted': an interdisciplinary examination of the work-related challenges faced by irregular migrants", Journal of Vocational Behavior, Vol. 78 No. 3, pp. 381-389.

McDonald, J.T. and Valenzuela, M.R. (2017), "How does skills mismatch affect remittances? A study of Filipino migrant workers", Contemporary Economic Policy, Vol. 35 No. 1, pp. 216-231.

McGuire, D. and Lozada, M. (2017), “I'll do it step by step': care, cover and quiet campaigning”, Work, Employment and Society, Vol. 31 No. 1, pp. 175-184.

McKenna, S. and Richardson, J. (2016), "Self-initiated expatriation: changing the ontological and methodological box", Qualitative Research in Organizations and Management, Vol. 11 No. 3, pp. 150-168.

McNulty, Y. and Brewster, C. (2017), "Theorizing the meaning(s) of 'expatriate': establishing boundary conditions for business expatriates", The International Journal of Human Resource Management, Vol. 28 No. 1, pp. 27-61.

Morgan, A. and Finniear, J. (2009), "Migrant workers and the changing psychological contract", Journal of European Industrial Training, Vol. 33 No. 4, pp. 305-322.

Mulinari, P. (2015), "Exploring the experiences of women and migrant medical professionals in Swedish hospitals visible and hidden forms of resistance", Equality Diversity and Inclusion, Vol. 34 No. 8, pp. 666-677.

Murray, P.A. and Ali, F. (2016), “Agency and coping strategies for ethnic and gendered minorities at work", The International Journal of Human Resource Management, Vol. 28 No. 8, pp. 1236-1260.

Neiterman, E. and Bourgeault, I.L. (2015a), "Professional integration as a process of professional resocialization: internationally educated health professionals in Canada", Social Science and Medicine, Vol. 131, pp. 74-81.

Neiterman, E. and Bourgeault, I.L. (2015b), "The shield of professional status: comparing internationally educated nurses' and international medical graduates' experiences of discrimination", Health, Vol. 19 No. 6, pp. 615-634.

Neubecker, N. (2014), "Two new datasets on south-north migration by occupational category", International Journal of Manpower, Vol. 35 No. 6, pp. 834-872.

Neville, F., Orser, B., Riding, A. and Jung, O. (2014), "Do young firms owned by recent immigrants outperform other young firms?”, Journal of Business Venturing, Vol. 29 No. 1, pp. 55-71.

Ortlieb, R., Sieben, B. and Sichtmann, C. (2014), "Assigning migrants to customer contact jobs: a context-specific exploration of the business case for diversity", Review of Managerial Science, Vol. 8 No. 2, pp. 249-273.

Oswick, C. and Noon, M. (2014), "Discourses of diversity, equality and inclusion: trenchant formulations or transient fashions?”, British Journal of Management, Vol. 25 No. 1, pp. 23-39.

Ozkan, U.R. (2018), "Foreign qualification recognition regimes for internationally trained professionals: the case of pharmacists", Journal of International Migration and Integration, Vol. 19 No. 2, pp. 367-389. 
Ponzoni, E., Ghorashi, H. and van der Raad, S. (2017), "Caught between norm and difference: narratives on refugees' inclusion in organizations", Equality Diversity and Inclusion, Vol. 36 No. 3, pp. 222-237.

Przytuła, S. (2015), "Migrants, assigned expatriates (AE) and self-initiated expatriates (SIE)Differentiation of terms and literature-based research review", Journal of Intercultural Management, Vol. 7 No. 2, pp. 89-111.

Rafferty, A. (2012), "Ethnic penalties in graduate level over-education, unemployment and wages: evidence from Britain", Work Employment and Society, Vol. 26 No. 6, pp. 987-1006.

Ressia, S., Strachan, G. and Bailey, J. (2017a), "Going up or going down? Occupational mobility of skilled migrants in Australia”, Asia Pacific Journal of Human Resources, Vol. 55 No. 1, pp. 64-85.

Ressia, S., Strachan, G. and Bailey, J. (2017b), "Operationalizing intersectionality: an approach to uncovering the complexity of the migrant job search in Australia", Gender Work and Organization, Vol. 24 No. 4, pp. 376-397.

Riano, Y., Limacher, K., Aschwanden, A., Hirsig, S. and Wastl-Walter, D. (2015), "Shaping gender inequalities: critical moments and critical places", Equality Diversity and Inclusion, Vol. 34 No. 2, pp. 155-167.

Rissing, B.A. and Castilla, E.J. (2016), "Testing attestations: us unemployment and immigrant work authorizations", Ilr Review, Vol. 69 No. 5, pp. 1081-1113.

Ryba, T.V., Stambulova, N.B. and Ronkainen, N.J. (2016), "The work of cultural transition: an emerging model", Frontiers in Psychology, Vol. 7, p. 427.

Sacco, J.M., Scheu, C.R., Ryan, A.M. and Schmitt, N. (2003), “An investigation of race and sex similarity effects in interviews: a multilevel approach to relational demography", Journal of Applied Psychology, Vol. 88 No. 5, p. 852.

Sang, K., Al-Dajani, H. and Ozbilgin, M. (2013), "Frayed careers of migrant female professors in British academia: an intersectional perspective", Gender Work and Organization, Vol. 20 No. 2, pp. 158-171.

Schultz, T.W. (1961), "Investment in human capital", The American Economic Review, Vol. 51 No. 1, pp. 1-17.

Shaffer, M.A., Kraimer, M.L., Chen, Y.P. and Bolino, M.C. (2012), "Choices, challenges, and career consequences of global work experiences: a review and future agenda", Journal of Management, Vol. 38 No. 4, pp. 1282-1327.

Shore, L.M., Randel, A.E., Chung, B.G., Dean, M.A., Holcombe Ehrhart, K. and Singh, G. (2011), "Inclusion and diversity in work groups: a review and model for future research", Journal of Management, Vol. 37 No. 4, pp. 1262-1289.

Silvanto, S., Ryan, J. and McNulty, Y. (2015), "An empirical study of nation branding for attracting internationally mobile skilled professionals", Career Development International, Vol. 20 No. 3, pp. 238-258.

Srour, F.J., Srour, I. and Lattouf, M.G. (2017), "A survey of absenteeism on construction sites", International Journal of Manpower, Vol. 38 No. 4, pp. 533-547.

Stankovic, M., Angelova, B., Janeska, V. and Stankovic, B. (2013), "Brain drain as brain gain in Southeast Europe: challenges ahead", Proceedings of the International Conference on Innovation and Entrepreneurship, pp. 109-118.

Syed, J. (2008), "Employment prospects for skilled migrants: a relational perspective", Human Resource Management Review, Vol. 18 No. 1, pp. 28-45.

Tajfel, H. and Turner, J. (1986), "The social identity theory of intergroup behaviour", in Worchel, S. and Austin, W.G. (Eds), Psychology of Intergroup Relations, Nelson Hall, Chicago.

Tani, M. (2020), "Migration policy and immigrants' labor market performance", International Migration Review, Vol. 54 No. 1, 0197918318815608.

Tatli, A. and Özbilgin, M.F. (2012), "An emic approach to intersectional study of diversity at work: a Bourdieuan framing”, International Journal of Management Reviews, Vol. 14 No. 2, pp. 180-200.
Theories for studying qualified immigrants 
EDI 41,7

te Nijenhuis, J., van Dam, K., Aarts, S. and van der Flier, H. (2014), "Selectors' decision strategies when assessing immigrant job applicants", International Journal of Selection and Assessment, Vol. 22 No. 1, pp. 88-100.

Tesluk, P.E. and Jacobs, R.R. (1998), "Toward an integrated model of work experience", Personnel Psychology, Vol. 51 No. 2, pp. 321-355.

Thomson, K. and Jones, J. (2015), "Being and becoming a professional accountant in Canada mimicry and menace in the transitions of migrant accountants", Critical Perspectives on International Business, Vol. 11 No. 2, pp. 156-+.

Toh, S., Connell, J. and Quinlan, M. (2009), "Safeguarding the global contingent workforce? Guestworkers in Australia”, International Journal of Manpower, Vol. 30 No. 5, pp. 453-471.

Turner, J., Hogg, M., Oakes, P., Reicher, S. and Wetherell, M. (1987), Rediscovering the Social Group: A Self-Categorization Theory, Blackwell, New York.

van den Broek, D. and Groutsis, D. (2016), "Global nursing and the lived experience of migration intermediaries”, Work, Employment and Society, Vol. 31 No. 5, pp. 851-860.

Weick, K.E. (1995), Sensemaking in Organizations, Sage, Thousand Oaks.

Winterheller, J. and Hirt, C. (2017), "Career patterns of young highly skilled migrants from Southeast Europe in Austria", Personnel Review, Vol. 46 No. 2, pp. 222-236.

Yakushko, O. (2010), "Clinical work with limited English proficiency clients: a phenomenological exploration”, Professional Psychology-Research and Practice, Vol. 41 No. 5, pp. 449-455.

Zikic, J. (2015), "Skilled migrants' career capital as a source of competitive advantage: implications for strategic HRM", International Journal of Human Resource Management, Vol. 26 No. 10, pp. 1360-1381.

Zikic, J., Bonache, J. and Cerdin, J.L. (2010), “Crossing national boundaries: a typology of qualified immigrants' career orientations”, Journal of Organizational Behavior, Vol. 31 No. 5, pp. 667-686.

Zimmermann, A. and Ravishankar, M.N. (2011), "Collaborative IT offshoring relationships and professional role identities: reflections from a field study", Journal of Vocational Behavior, Vol. 78 No. 3, pp. 351-360.

\title{
Appendix
}

The appendix is available online for this article.

\begin{abstract}
About the authors
Ali Dehghanpour Farashah is an Assistant Professor at the School of Business, Society and Engineeringurgh at Mälardalen University, Sweden. His research interests are primarily in career. He is also interested in research on diversity and inclusion, ethics and corporate responsibility. His research has published in human resource and organisational behaviour journals such as Personnel Review, Evidence-based HRM, Education and Training and also International Journal of Project Management. Ali Dehghanpour Farashah is the corresponding author and can be contacted at: ali.farashah@mdh.se

Tomas Blomquist is a Professor and at School of Business, Economics and Statistics at Umeå University. His current research interests include career of qualified immigrants in Sweden and business incubation.
\end{abstract}

For instructions on how to order reprints of this article, please visit our website:

www.emeraldgrouppublishing.com/licensing/reprints.htm

Or contact us for further details: permissions@emeraldinsight.com 